\title{
Value Co-Creation and Co-Destruction in Online Video Games: An Exploratory Study and Implications for Future Research
}

\author{
Jarkko Kokko \\ University of Vaasa \\ jarkko.kokko@outlook.com
}

\author{
Tero Vartiainen \\ University of Vaasa \\ tero.vartiainen@uwasa.fi
}

\author{
Tuure Tuunanen \\ University of Jyväskylä \\ tuure@tuunanen.fi
}

\begin{abstract}
In this empirical study we studied how players of online video games co-create and co-destroy value. From players' perceptions we identified that value co-creation and co-destruction occur amid themes of giving feedback and building relations. Feedback encourages players but it may also be harmful in the form of verbal abuse. Building relations relates to making friends in general but also on an international level. Building relations also relates to competition that creates a bad spirit. The most intensive interplay between value co-creation and codestruction was found in gaming groups. Gaming groups motivate players to engage in intense gameplay, but at the same time they are resourcedemanding with respect to time and mental capacity. In conclusion, we argue that further study is required of the ways that value co-creation and co-destruction interact in online video games.
\end{abstract}

\section{Introduction}

Our study concerns value co-creation and codestruction in online video games. Video games are goal- and experience-driven products, where a social component exists if the cooperative aspect of a game requires it, meaning players must work together to achieve goals and progress in the game world. According to the Oxford dictionary, a video game is defined as follows [1]: "A game played by electronically manipulating images produced by a computer program on a monitor or other display." An online video game, then, is a video game played via the Internet. We take the viewpoint that value is cocreated and co-destroyed in the social interaction of gaming between the players of online video games that have a social component.

Studying the social aspect of games has been promoted; investigation of social gratification and motivation in games is perceived as essential [2], for example. Indeed, the social aspect of games has been studied in scientific literature [e.g., 3, 4]. As an example, player types were studied by [3] and synthesized into five motivations to play: achievement, exploration, sociability, domination, and immersion. According to our interpretation, sociability and domination refer to social aspects and we speculate that these two motivations may be linked to positive and negative social outcomes in games.

Regarding positive outcomes, [5] studied social interactions encountered in massively multiplayer online role-play games (MMORPGs). Part of their study focused on whether players had ever made friends from MMORPGs and then met them in real life. They found that over $76.2 \%$ of male and $74.7 \%$ of female players had made good friends by playing MMORPGs. They also found that $67.4 \%$ thought playing the same game with others had a positive influence on their friendship.

A study by [6] considered the benefits of playing video games, and they focused on cognitive, motivational, emotional, and social benefits. Social benefits included an increase in prosocial behavior when playing games. They also pointed out how gaming experiences can vary based on the social partners the games are played with.

Regarding negative outcomes, [7] examined antisocial behavior in online video games by studying perceptions of League of Legends players. The game is a team-based game, where two teams consisting of five players battle against one another and try to win the match. Players reported that toxic antisocial behavior clearly weakens the odds of winning the game and affects the mood of every teammate, even if negative discussion is only taking place between two players. As another example, [8] found that verbal aggression and group size had a significant positive relationship with hostility in group-based video games.

Considering the existing literature on social viewpoints toward online video games, we argue that 
development of these games could benefit from research that takes value co-creation and value codestruction viewpoints into consideration. Understanding how value is co-created and codestroyed makes it possible to design means to support creation and prevent destruction of value in these games. Thus, our study posits the following research questions:

- How do value co-creation and value codestruction occur in an online video game?

- What means are there to consider the interaction between value co-creation and codestruction?

To answer these questions, we adopted an interpretive approach [9] and interviewed 6 players of an online video game. Based on interpretive analysis, we formed two sets of categories on value cocreation and value co-destruction. In addition, existing means to consider value co-creation and destruction are reported. Based on the results, we offer research implications that are focused on development of online video games from value cocreation and co-destruction viewpoints.

After this introduction, the theoretical frameworks for value co-creation and co-destruction are presented. Then, research design is presented. In the results section, we highlight preliminary findings from the interviews. Finally, we discuss the results and conclude.

\section{Value Co-Creation and Co-Destruction}

The co-creation of value is a fundamental thesis in modern approaches to service research and service-dominant logic [10]. Value co-creation is thought to occur through the interaction between the service provider and the service user. This process is also linked to the service experience of the user and the intangibility of the services (i.e., the service happens at a certain time in a designated place and cannot be stored in situ).

More specifically, Tuunanen et al. [11] argued that value co-creation for users is an interplay of at least two issues. First, a service system, like a social online game, offers value propositions to the users, and second, the users possess values or goals that drive their behavior. Tuunanen et al. [11] have claimed that users can potentially have an identity [see, e.g., 12] attached to the digital artifacts they use. Lamb and Kling [13] have further argued that actors use these artifacts to form and construct identities for themselves and that the use of such systems is a social act. Finally, Tuunanen et al. [11] have highlighted the importance of the context of system use [see, e.g., 14] for value co-creation.
Tuunanen et al. [11] have also suggested that there are three key value drivers for users. First, they referred to the "service process experience" (i.e., how users experience the service in situ). Holbrook et al. [15] proposed the notion of "playful consumption," in which play becomes a part of the service experience. Holbrook et al. studied the effects of emotions, performance, and personality on value creation in games. Second, according to servicedominant logic, value is co-created, and the total value of the offering is determined by the user while the service is in use $[10,16]$. Information systems (IS) researchers have long promoted the participation of users in systems development [17]. Third, in IS research, there has been also a strong tradition of using the perceived usefulness of IS as a success metric [18], and more recently, the hedonic side of value has been explored as well [19-21]. Kahneman et al. [22] have also suggested that users derive not only utility from consumption but also hedonic benefits and goals.

However, while extant literature often refers to value co-creation in an intrinsically positive manner, and engagement in interactive value creation processes has also mainly been explained in an unproblematic way $[10,16]$, users' service encounters do not always have positive outcomes $[23,24]$. This duality of value creation and destruction has also been recognized in the literature, which has stated that, in interactive value creation, value destruction exists as an opposing phenomenon to value co-creation [25, 26]. Plé and Chumpitaz [26] define value co-destruction as "an interactional process between service systems that results in a decline in the well-being of at least one of the systems, which, given the nature of a service system, can be individual or organizational." According to [26], such co-destruction of value behavior can be (i) intentional use or (ii) unintentional, depending on the motivations and actions of the service systems (i.e., the humans or the systems).

So far, we have conducted multiple case studies with the purpose of studying both value co-creation and co-destruction from the perspective of different industry domains to develop a theoretical framework for digital service users' value-creation behavior. This work has provided not only a solid foundation for gaining a more refined view of value creation for different digital services, but also a platform for more formative work in terms of theory development. Furthermore, our work with contradictions in IT artifact use [24] has led us to the development of a process-based framework for value co-destruction $[23,27]$, which looks at different internet-of-things enabled services and cyber physical systems [28]. 
However, during the past years, we have realized that value co-creation and co-destruction are like yin and yang $^{1}$, dynamically interacting with each other (weakening or strengthening, cf. [29-31]) during service encounters by users and service providers and that these should not be studied separately. To address this issue, we have studied social online games to further understand this dynamic of value co-creation and co-destruction. This work is reported here.

\section{Research Method}

This research is interpretive in nature [9], and employed interviews to gather data. The first author has played online video games for roughly 15 years from various game genres, and he conducted the interviews. His experience made it possible to understand expressions and terms used by the interviewees. He also used his knowledge and perceptions about online video games when analyzing interview data. In recruitment of subjects, the goal was to keep the gender distribution even. This was achieved, and the total number of subjects was six (females $n=3$, males $n=3$ ). The subjects were aged between 22 and 37 years. When selecting the subjects, one criterion was that all participants must be over 18 years old. The next criterion was the amount of time the subject had spent playing online video games. Since the initial impression of a product or a service can be judged quite fast, it was determined that if a subject had spent more than a few hours per week playing online video games, he or she was qualified for the interview. All participants had played online video games several hours per week at some point in their lives, so this criterion was fulfilled by all participants.

The interview questions were delivered to the subjects in advance a few days prior to the actual interview to ensure the subjects had time to familiarize themselves with the actual research and to avoid any "surprise" effect. Participants were also asked to choose one game and describe its overall social atmosphere and player community.

The interview questions asked subjects to express their views on value co-creation and value codestruction in online video games:

- Have you ever encountered positive or negative social interaction in online video games? Has this interaction been directed specifically at you,

\footnotetext{
${ }^{1}$ See, e.g., https://en.wikipedia.org/wiki/Yin_and_yang
}

or has the interaction been between two other parties?

- Do you feel positive or negative social interaction has somehow influenced whether you like some video game or not?

- For example, have you gotten more interested in playing a certain video game because of positive social interaction? Can you describe this briefly?

- On the other hand, have you reduced playing, or even stopped playing altogether, some online video game because of negative social interaction? Can you describe this briefly?

- Pick an online video game you have played at some point in your life. Describe briefly the overall social atmosphere and the player community of this game.

Given that there is a need to consider interaction and support positive interaction, we asked the subjects to consider the responsible parties of gaming communities, regulations, and sanctions:

- Who do you think is responsible for improving and maintaining the overall mood of the gaming community?

- In what way should the gaming community, player behavior, and mood of the community be policed or regulated?

- What are proper sanctions for players who behave badly? What about good behavior, should it be rewarded?

In addition, probing questions such as "describe $\mathrm{X}$ more" or "could you elaborate this further" were also used during interviews.

To analyze the data, the interview recordings were partially transcribed. Rather than making a full transcription of the interview recordings, the interviewer made notes and brought up the highlights of each question. When analyzing the data, the exact quotes and points were always traced from the recordings.

After the transcription process was done, the research results were categorized by using conventional content analysis, that is, a data-driven approach [32]. In addition, value co-creation and value co-destruction frameworks were used to identify how value is created and destroyed in social behavior between players. First, the perceptions were split between positive and negative topics because the interviews were constructed such that positive and negative social interactions were discussed separately. While reading and making interpretations we found that there were major themes that had both positive and negative sides and that represented more or less socially complex phenomena. The major themes were revealed to be communication between players, relations between players, and intensive team 
performance. After this, we identified social mechanisms for considering the issues of social interaction. Next, the results are reported.

\section{Results}

The subjects were asked to name a few of the online video games they have played. These games represented various and differing game genres: first person shooting games (Call of Duty franchise, Counter Strike, Doom 1, Left 4 Dead franchise, Paladins), massively multiplayer online role-playing games (MMORPGs) (World of Warcraft, Guild Wars series, Star Wars: The Old Republic), multiplayer online battle arenas (League of Legends, Heroes of the Storm), online collectible card video game (Hearthstone), multiplayer survival video games (Rust, Terraria), and massively multiplayer online games (Subspace and World of Tanks). The subjects reflected their social gaming experiences with these games. Some subjects concentrated more on one game, while others gave answers and examples from a wider set of online video games.

Table 1 summarizes our interpretation of value co-creation and value co-destruction in online video games. We identified three simplified themes of value formation: (i) communication between players, (ii) relations between players, and (iii) performing on a team. In each of these themes value co-creation and co-destruction may occur. The themes are overlapping, meaning that behaviors described in a theme may affect behaviors in another theme. Next, we report positive and negative social interactions in detail. After that social mechanisms for upholding value formation are presented.

Table 1. Value co-creation and co-destruction in online video games

\begin{tabular}{|l|l|l|}
\hline $\begin{array}{l}\text { Themes of } \\
\text { value } \\
\text { formation in } \\
\text { online video } \\
\text { games }\end{array}$ & $\begin{array}{l}\text { Positive social } \\
\text { interaction (value } \\
\text { co-creation) }\end{array}$ & $\begin{array}{l}\text { Negative social } \\
\text { interaction (value } \\
\text { co-destruction) }\end{array}$ \\
\hline $\begin{array}{l}\text { Communication } \\
\text { between players }\end{array}$ & Positive feedback & $\begin{array}{l}\text { Negative feedback; } \\
\text { Verbal abuse }\end{array}$ \\
\hline $\begin{array}{l}\text { Relations } \\
\text { between players }\end{array}$ & $\begin{array}{l}\text { Making friends; } \\
\text { Possibility to form } \\
\text { international } \\
\text { friendships }\end{array}$ & $\begin{array}{l}\text { Competition causes } \\
\text { bad spirit; } \\
\text { Negative social } \\
\text { experiences cause } \\
\text { change in game } \\
\text { mode }\end{array}$ \\
\hline $\begin{array}{l}\text { Performing on a } \\
\text { team }\end{array}$ & $\begin{array}{l}\text { Gaming groups } \\
\text { inspire }\end{array}$ & $\begin{array}{l}\text { Gaming groups } \\
\text { cause too much } \\
\text { pressure }\end{array}$ \\
\hline
\end{tabular}

\subsection{Positive social interaction}

4.1.1. Communication between players (positive). Positive feedback was seen to be encouraging and empowering, and subjects clearly demonstrated how overall positive feedback and positive social interaction in online video games encouraged them to play more. This encouragement also boosted more impulsive continuation of the playing process, where the well-played match and the positive feedback often drove subjects to keep on playing. "Positive interaction tends to be less, because people don't usually say it out loud" (F3). This quote suggests that positive feedback does exist.

4.1.2. Relations between players (positive). Making friends was the most frequent theme when discussing positive social interactions. This theme eventually branched out to several subthemes. Acquiring friends, being able to play with others, or being able to socially interact with like-minded people in online games was mentioned by many subjects. Friends could be either those a person had met in real life and started playing with, or friends could have been acquired from the gaming community. Whatever the case, playing games with friends or like-minded people boosted the value of the game, enhanced gaming experiences, and increased the time spent gaming.

"The game (Subspace) is really simple and straightforward, which is enjoyable as it is, but the big part of the gaming experience comes from the interaction of other players in spectator mode, where you don't actively play the game, but rather just watch when others are playing while you talked with other players in spectator mode. - If the social community had been absent from the game and one had no means to communicate with others, I probably wouldn't have played the game for more than a couple days" (M1).

In some cases, the game acted as a discussion client, and like the quote above, the social community was a crucial part for the subject. It is safe to say that the social community alone was a major force that brought players back again and again to play the game.

"At the moment I play pretty much the same games as my friends want to play-then you have that same trustworthy team with you which you do not need to be worried about" (F3).

Playing with friends was also seen as a comforting and reassuring factor, since the player already knows the playing partner a little. In games that allow players to work together toward a common 
goal, it may be easier to share responsibilities and tasks with the people you already know.

"The reason why I play online video games is the company. I would not play those games if there were no chance to play them with friends-social aspect is what drives (me) to play" (M2).

All the quotes regarding friends give us a clear message of how important a factor the social aspect of online video games is. The nature and gaming type of the online video game dictates what kind of interaction a video game enables. For example, MMORPGs simply cannot function without the social component, because the goal is to accomplish quests together and spend hours playing the game.

Some subjects gave the impression that these friends are only available through online video games, meaning any further contact information is not exchanged. Some kept contact with these friends by social media or other online communication tools existing outside the video game, and some have even met these new friends face to face. One subject told that social interaction has brought positive things to her life (like stress relief), and because of this, the subject was also more likely to get back to playing games. Regarding value formation, this is an important discovery because co-creation of value emphasizes how the value in a game is created socially in many ways.

Friends could be made around the world, and this is called internationalization. Internationalization was considered a positive "side effect" by many subjects, and reasons for this varied. Thinking globally and getting to know new, interesting cultures was an example.

"Our guild has these real-life meetings each year in some member's home country-these experiences are kind of internationalization and "global way of thinking"-if you think (some other hobbies) like going to gym or something else, you probably don't have same chances at meeting people from so many different cultures-all this is open to everyone if you have a computer and are willing to play. Requirements to participate are low" (F1).

This quote gives a good example of how online friendships can also turn out to be real-life friendships, despite that people live far from each other. Playing with foreign friends can encourage thinking differently and more openly.

"Well while playing Left 4 Dead video game I met other players from different European countries, and then just kept adding them to my friends list on Steam. After that I did not need to wait for my Finnish friends to come and play, but I was able to go and play with the international group. So this alone added at least tens of hours of game play to, well, for example to Left 4 Dead" (M3).

Being able to play with foreign players was seen as a nice "bonus," which enriched the gaming experience, brought added value to a process of playing the game, and increased the time spent playing online video games.

4.1.3. Performing in team (positive). The gaming groups can be, for example, a group of friends who play a game together, a guild formed by a group of MMORPG players, or a clan in an online FPS game.

"[In our guild] we had sort of military ranks, where each member had a clear role and responsibilities - there was kind of social pressure to benefit the guild and act towards common goals" (M2).

"We have the active guild founded 11 years ago. If this guild would not exist, I wouldn't have played Guild Wars nearly as much as I have now" (F1).

The subjects gave an idea of how important the gaming group was, and how it was a big motivator to return to play the game. A gaming group can be seen as any other social group formed around the same interests; gaming groups just happen to be established for gaming and bringing like-minded players together. One subject brought up the point that guilds dedicated to the same game can have different characteristics. In MMORPGs, a guild may be focused on more player-versus-player type of gameplay or player-versus-environment, where the point is to explore the game world together and not to battle against other players.

\subsection{Negative social interaction}

4.2.1. Communication between players (negative). Negative feedback was the most frequent negative theme in the research data. The nature of negative feedback varied between the subjects. In most cases, subjects reported the negative feedback was something that had to do with the way the subject was playing the game.

"Of course every (online) video game has those players who are sharing their 'expert' opinions in every situation" (F3).

There was a clear difference in the content of messages between the good and the bad feedback. Tendencies to point out mistakes and criticize the player's playing style were seen in a negative way.

"If there were new players asking for advice, others often willingly helped and answered those questions" (F3).

The friendliness toward new players was one of the key points where the negative feedback was 
brought up. The subjects reported that at times there were huge differences between different games on how "beginner questions" were treated and what kind of answers new players got to those questions. This can be a damaging factor for a game's value, if new players feel they are not welcome, or if they are driven off some other way.

Verbal abuse was mentioned usually at the same time that subjects discussed the negative feedback in general. Verbal abuse often was more personal, with the intention to offend others.

"Basic name calling and trolling are most often part of the game" (M2).

The quote above gives a bit of a gloomy message about how players have grown to accept negative social behavior and direct verbal abuse as part of the gaming experience in some games. The positive side that came up during interviews was that no one gave any examples of verbal abuse. Rather, everyone who brought verbal abuse up gave only general characterizations about the issue and acknowledged the presence of the issue. However, when discussing the verbal abuse, the subjects did not convey any strong feelings of being hurt deeply. This could mean the verbal abuse has not left any long-term mental scars on the subjects; otherwise subjects would most likely remember and point out these occurrences. While the quote below discusses negative behavior in general, it could also support the theory that negative feedback and verbal abuse are forgotten quickly.

"That [negative interaction] may make me to not want to play the game for a while if negative feedback has been plentiful, but after that you usually forget about it and return to play" (F2).

4.2.2. Relations between parties (negative). Some subjects brought up the competitiveness and the competitive nature of video games as one cause of negative social behavior. The competitiveness stems from playing against other players while having competitive components present in the game. Most often this component was the possibility to advance in the leader boards and/or scoring points and acquiring a rating. A rating is most often seen as a representation of a player's skill level, so the higher the rating level, the better skilled the player.

"I have noticed how the mood can get heated when playing hardcore player versus player-type game mode, which is really competitive in nature" (F1).

Competitiveness was presented as one of the causes for negative feedback and verbal abuse. When playing competitively, the players most often take gaming more seriously, because a competitive play offers a way to measure your own performance in the game. This can therefore lead us to a conflict of motives, where one player might be aiming to improve his or her play style and become the best player, while others have humbler goals and are only seeking to find out how high or low they can score with their present skills and might not necessarily be looking to improve or advance their skills or rating.

These types of conflicts are an extremely potent way of causing heated arguments and outright verbal abuse, when hopes, goals, and intentions are not aligned between players who are playing on the same side. The level of emphasis on team play is also important to note here, as many team-based online video games truly require players to work together toward common goals and the possibility of so-called "solo play" or "carrying" (a player's ability to bring the team to victory all by oneself) is nonexistent.

From the value co-destructive perspective, we can see a clear conflict in goals and intentions here. The original goal in having a more competitive way of playing is to give players a more "serious" game mode, allowing "hard-core" players to get increased value from the game. However, the conflicts in goals and intentions may seriously destroy the value of the game for other players.

The role of competitiveness in negative feedback can be much more substantial than it originally might seem to be.

"Negative social experiences have not pushed me away from any game, but it has guided me to play more certain game modes. - I have consciously avoided these player versus player-type game modes because of negative social experiences" (F1).

While not the most prominent theme in the research data, social experiences have directed subjects toward certain game modes while avoiding those game modes that provided negative social experiences in the past. Game mode relates to game play modes within the same game. For example, they may have different rules (e.g., Deathmatch, Capture the flag) or different opponents (e.g., player vs. player, player vs. computer), or a player's skill could be measured (e.g., ranking). With respect to game modes, one subject declared that negative social experiences have influenced her decision to choose certain game modes. This matter, however, could be a much more prominent issue if subjects were asked specifically how they select their preferred game mode in one online video game.

When players feel they are forced out of the game mode they would like to play, we can assume value destruction has occurred. On the other hand, if players feel they can move between game modes and keep playing the game they like, despite the fact some parts of the game provide negative experiences, 
value destruction is not happening, or at least it is not as severe as if players were forced out of the game mode they prefer or out of the game completely. So much of this is a matter of perspective.

4.2.3. Performing in team (negative). Gaming groups were discussed earlier in themes related to positive social interaction, but during the interviews gaming groups were also revealed to have a negative side.

"The social pressure around the game grew too big for me-clan and the social community was so tightly knit together-the game would have required much more intensive attitude and more time to play, and I just didn't see a point why to continue anymore" (M2).

The quote above is a clear example of how the gaming community can be a negative factor in value formation and creation. One subject reported the time required to play the game by the clan was one of the reasons why he eventually stopped playing. While most of the time changes in life can be the simple explanation for why people don't have time for hobbies as they used to, it can also be that the community around the hobby is too demanding and wants subjects to spend more and more time and resources on the common hobby.

Most often MMORPG- and MMO-type games have more than just one clan or guild to choose from, and these communities usually have emphases on different things, so the solution to peer pressure from one clan could be fixed by changing to another clan more suited to a player's preferences.

The negative side of gaming groups is an important factor to consider when analyzing social experiences in online video games, while at the same time remembering that in most cases the positive factors usually outweigh the negatives. This was also pointed out by the subjects. For game developers, the clans and guilds as value creators and value destroyers are in most cases out of reach, since especially the bigger gaming groups have their own external websites, organizations, and communication channels through discussion boards and other programs.

Gaming groups are a good example where value co-creation and co-destruction can occur at the same time. Gaming groups are also a good example of how factors not directly accessible or controllable by the producer of a service can significantly enrich or hinder value co-creation or co-destruction process.

\subsection{Social mechanisms for value formation}

4.3.1. Monitoring and reporting systems. According to the subjects, the game creator should provide some tools to give empower players, such as a simple reporting system, where players are able to report negative players to game developers. Many subjects acknowledged that game developers simply cannot monitor everything, as many online video games can have thousands of matches ongoing at the same time, and sometimes concurrent players are counted in the millions. The subjects suggested that players should have more power and possibilities to influence the gaming experience by being able to report players who misbehave.

"Of course the game developer has to have some part in this, but also they simply cannot monitor everything and see everything, so players have big responsibility too to give feedback. Otherwise the developers cannot know what is happening all the time" (F3).

One subject looked at the issue from the gaming group point of view, and stated how important the leadership of the guild is in building up and fostering a good community. Some subjects suggested that a game developer should provide tools for players to monitor gaming communities and, if needed, to take action against misbehaving players. If the gaming community is outside of the developers' reach (like clans or guilds), it should be up to the gaming group itself to monitor and control behavior.

4.3.2. Sanctions and rewards for negative and positive social behavior. "Either complete ban from the game, or temporary block of some sort, depending what kind of offense is in question" (F1).

Before the interview ended, the subjects were also asked their opinions about rewards and punishments for positive and negative social behavior. When discussing appropriate sanctions for negative social behavior, the most recurring option was banning the offender from the game, either permanently or for a set period of time, depending on the nature and gravity of the offence.

The alternative option to banning the player from the game was limiting the offender's game experience for a certain time. This was presented as a light option, where the offender must have some sort of punishment as a wakeup call for his or her actions, but does not necessarily deserve a full ban from the game. Ways to limit the gaming experience were also suggested. One way was to limit interaction possibilities. For example, if the offender misbehaves in the text chat of the game, the offender's access to text chat could be denied for certain time period. 
A second option was to have sanctioning mechanisms built in, so as to warn players that "your deeds have consequences." This could also be called the social rating system. When a player misbehaves, co-players are able to rate his or her performance and give negative points to the negative player. When the player has accumulated enough negative points, the game starts to automatically deal sanctions.

The opinions about rewarding positive social behavior were much more divided among the subjects. Some thought it would be a good idea to share "positivity points" with the players, while others said the positive behavior should not be rewarded.

The persons who supported rewarding positive behavior also suggested that the positivity would have some real benefits. One suggestion was that when players accumulate enough of these positivity points, they would obtain some in-game content not available in any other way as a reward. Examples of these suggestions include custom cosmetic enhancements for player characters, custom avatar pictures, and so forth. These cosmetic rewards would be purely aesthetic in nature, and would not give any performance boost in the game.

Another suggestion regarded how the positive behavior would be visible to others. This was seen as a benefit in situations where players are assembling gaming teams, so a visible behavior score would act as an indicator of a player's social habits. The player who has a lot of negative social points would be a less preferable player compared to one with a high social score.

"This is only my opinion, but I think rewarding players from good behavior is not necessary... ...Sometimes (if game has rewarding system for good behavior) players share positivity points to others even if players simply were not utter nuisance to each other-like in real life people do not come and thank you for not being horrible to others!'”(M3).

Some subjects felt positive behavior should be seen as something that is expected as a standard from all players, not something that should specifically be rewarded. In other words, a positive and healthy gaming community and a good gaming experience should be enough of a reward itself. One subject used World of Tanks as an example, and stated that in the game, good behavior is when players try to work together to win the match. This is something that is expected from everyone. Hence, some subjects felt good behavior is something every normal person should be capable of and thus should not be rewarded.

In summary, sanctions for bad behavior were strongly supported by the sample group. While some suggested more traditional ways of punishing players, like banning and blocking from the game, new ways such as limiting the gaming experience or having a "deeds have consequences"-type of automatic game limiter were also proposed. Rewarding positive social behavior did divide the sample group more, where some liked the idea of rewarding positive players but others disliked it for valid reasons.

\section{Discussion and Conclusions}

We identified three simplified themes important to value co-creation and co-destruction that occur in online video games: communication between players, relations between players, and gaming groups. We found that in gaming groups, interaction between value co-creation and co-destruction is most intensive. Our results supplement the studies on social aspects of games suggested by [2], for example.

\subsection{Implications for future research}

We believe that consideration of value co-creation and co-destruction will benefit game studies; therefore, based on our results, we propose four implications for future research.

5.1.1. Contradictions of online games. Our results revealed that players experience both positive and negative social interaction, both of which were intensively present in gaming groups: While gaming groups inspire players they may also cause peer pressure among them. This finding suggests that there may be contradictions (structural tensions) [33] in online video games; by identifying contradictions in online video games it is possible to develop them (cf. [24]).

5.1.2 Process model for value co-creation and codestruction in online games. Our results hinted at paths toward value co-creation and co-destruction. Negative social experiences (e.g., verbal abuse, too much pressure) may lead to a change of game mode, for example. Based on this finding, we speculate that the process model approach may benefit studies and the practice of online games. In a process model the basic elements are antecedent conditions, events followed by events, and outcomes together with environment [34]. We propose that events causing value co-creation and co-destruction should be further studied to understand what happens in time when value is created or destroyed. This information would make it possible to weaken value destruction and strengthen value creation. 
5.1.3. Social mechanisms for value formation. Based on our results, we speculate that social mechanisms (e.g., player rating systems) could be developed to support positive value formation and mitigate negative value formation. As with any social innovation, new social mechanisms might have positive and negative consequences for players, and those consequences may be intentional or unintentional [26]. Therefore, action research is needed to develop and test those mechanisms.

5.1.4. Player types and value co-creation and codestruction. Player types were studied by [3] and synthesized into five motivations to play: achievement, exploration, sociability, domination, and immersion. We speculate that further study between these motivations and value co-creation and co-destruction are in order to better understand how value is formed in online video games.

\subsection{Limitations}

First, because the interviews were open-ended, the data covered many different topics related to social interaction in video games and the data were scattered. A second limitation for the research was the small sample group $(N=6)$. The results, therefore, should be taken as exploratory and not confirmatory. Third, the first author's involvement in playing online video games is both a strength and a weakness. It is a strength that he knew the social setting and was able to explain the concepts the subjects used. It is a weakness in that close interaction in a familiar setting may blind a researcher to posing unconventional, probing questions, for example.

\subsection{Conclusions}

In conclusion, we see online gaming as a fruitful area for further research to understand how value is both co-created and co-destroyed by the users. We are also working on several other domains to study this, such as cyber physical systems-enabled services and mixed reality-enabled gaming, and social media services, where we also see value co-creation and codestruction behavior. Thus, we invite other researchers to join the effort to study the user behavior dynamics involved in value co-creation and co-destruction.

\section{References}

WWW-page 13th June 2017; https://en.oxforddictionaries.com/

[2] J. Hamari, \& L. Keronen (2017). "Why do people play games? A Meta-Analysis." International Journal of Information Management, 37(3), 125141

[3] J. Hamari, \& J. Tuunanen, (2014). "Player types: A Meta-synthesis." Transactions of the Digital Games Research Association, 1(2), 29-53

[4] K. P. Kallio, F. Mäyrä \& K. Kaipainen (2011). "At Least Nine Ways to Play: Approaching Gamer Mentalities." Games and Culture, 6(4) 327-353.

[5] H. Cole \& M. D. Griffiths (2007). "Social Interactions in Massively Multiplayer Online Role-Playing Gamers." Cyber Psychology \& Behavior 10: 4, 575-583.

[6] I. Granic, A. Lobel, \& R. C. M. E. Engels (2014). "The benefits of playing video games." American Psychologist, 69(1), 66.

[7] Y. Kou \& B. Nardi (2013). "Regulating AntiSocial Behavior on the Internet: The Example of League of Legends." iConfrence 2013 Proceedings, 616-622.

[8] M. S. Eastin (2007). "The influence of competitive and cooperative group game play on state hostility." Human Communication Research, 33(4), 450-466.

[9] G. Walsham. 2006. "Doing interpretive research.” Eur. J. Inf. Syst. 15, 3 (June 2006), 320-330.

[10] S. L. Vargo and R. F. Lusch, "Evolving to a New Dominant Logic for Marketing," Journal of Marketing, vol. 68, pp. 1-17, 2004.

[11] T. Tuunanen, M. Myers, and H. Cassab, "A Conceptual Framework for Consumer Information Systems Development," Pacific Asia Journal of the Association for Information Systems, vol. 2, p. 5, 2010.

[12] W. E. D. Creed, M. A. Scully, and J. R. Austin, "Clothes Make the Person? The Tailoring of Legitimating Accounts and the Social Construction of Identity," Organization Science, vol. 13, pp. 475-496, October 2002.

[13] R. Lamb and R. Kling, "Reconceptualizing Users as Social Actors in Information Systems Research," MIS Quarterly, vol. 27, pp. 197-235, June 2003.

[14] W. J. Orlikowski, J. A. Yates, K. Okamura, and M. Fujimoto, "Shaping electronic communication: the metastructuring of technology in the context of use," Organization Science, vol. 6, pp. 423-444, 1995.

[15] M. B. Holbrook, R. W. Chestnut, T. A. Oliva, and E. A. Greenleaf, "Play as a Consumption Experience: The Roles of Emotions, Performance, and Personality in the Enjoyment of Games," Journal of Consumer Research, vol. 11, pp. 728-739, September 1984.

[16] C. K. Prahalad and V. Ramaswamy, "CoCreation Experiences: The Practice in Value 
Creation," Journal of Interactive Marketing, vol. 18, pp. 5-14, Summer 2004.

[17] G. Davis, "Strategies for information requirements determination," IBM Systems Journal, vol. 21, pp. 4-31, 1982.

[18] V. Venkatesh, M. G. Morris, G. Davis, and F. Davis, "User Acceptance of Information Technology: Toward a Unified View," MIS Quarterly, vol. 27, pp. 425-278, 2003.

[19] H. Van der Heijden, "User acceptance of hedonic information systems," MIS quarterly, vol. 28, pp. 695-704, 2004.

[20] K. Valkonen, N. Lindström, L. Natunen, R. Isoviita, and T. Tuunanen, "Balance of Hedonic and Utilitarian Values in Information Systems Use," in Nordic Contributions in IS Research, ed: Springer, 2015, pp. 165-176.

[21] V. Venkatesh, J. Y. Thong, and X. Xu, "Consumer acceptance and use of information technology: extending the unified theory of acceptance and use of technology," MIS quarterly, vol. 36, pp. 157-178, 2012.

[22] D. Kahneman, E. Diener, and N. Schwarz, Eds., "Well-Being : The Foundations of Hedonic Psychology." New York, NY: Russel Sage Foundations, 2003, p.^pp. Pages.

[23] J. Lintula, T. Tuunanen, and M. Salo, "Conceptualizing the Value Co-Destruction Process for Service Systems: Literature Review and Synthesis," in the 50th Hawaii International Conference on System Sciences, Hawaii, Big Island, 2017.

[24] T. Vartiainen and T. Tuunanen, "Value CoCreation and Co-Destruction in an IS Artifact: Contradictions of Geocaching," in Hawaii International Conference on System Sciences, Hawaii, 2016, p. 10.

[25] P. Echeverri and P. Skålén, "Co-creation and codestruction: A practice-theory based study of interactive value formation," Marketing Theory, vol. 11, pp. 351-373, 2011.

[26] L. Plé and R. Chumpitaz, "Not always cocreation: introducing interactional co-destruction of value in Service-Dominant Logic. Keywords," Journal of Services Marketing, vol. 24, pp. 430437, 2009.

[27] J. Lintula, T. Tuunanen, M. Salo, and T. Kari, "Understanding Augmented reality game players' Value Co-Destruction Process in Pokémon GO," in 25th European Conference on Information Systems, Guimarães, Portugal, 2017.

[28] C. Peters, P. Maglio, R. Badinelli, R. R. Harmon, R. Maull, J. C. Spohrer, et al., "Emerging digital frontiers for service innovation," Communications of the Association for Information Systems, vol. 39, 2016.

[29] P. M. Bentler and C. Chih-Ping, "Practical issues in structural modeling," Sociological Methods \& Research, vol. 16, pp. 78-117, 1987.

[30] P. C. Reiss and F. A. Wolak, "Structural econometric modeling: Rationales and examples from industrial organization," in Handbook of econometrics, ed, 2007, pp. 4277-4415.

[31] M. Browning, "Two examples of structural modelling. Notes for "Structural modelling"," Department of Economics, University of Oxford, Oxford2012.

[32] Hsiu-Fang Hsieh and S. E. Shannon. 2005. "Three Approaches to Qualitative Content Analysis.\# Qual. Health Res. 15, 9 (2005), 12771288.

[33] Y. Engeström, "Learning by expanding: An activity-theoretical approach to developmental research." 1987, Helsinki: Orienta-konsultit.

[34] K. Lyytinen, \& M. Newman (2008). "Explaining information systems change: a punctuated sociotechnical change model." European Journal of Information Systems, 17(6), 589-613. 